\title{
Relationship between Food-frequency and Glycated Hemoglobin in Korean Diabetics: Using Data from the 4th Korea National Health and Nutrition Examination Survey

\author{
Kyoung-Lack Lee, Eui-Hyun Yoon, Hyang-Mee Lee, Hwan-Sik Hwang*, \\ Hoon-Ki Park
}

Department of Family Medicine, Hanyang University College of Medicine, Seoul, Korea

Background: This study was performed to evaluate the association between food intake frequencies and long-term blood glucose control using glycated hemoglobin (HbAlc) in Korean diabetes.

Methods: This study used data collected from the 4th Korea National Health and Nutrition Examination Survey. Patients with diabetes were defined as people who responded "yes" to the question "Are you currently suffering from diabetes?" or in whom serum fasting glucose was $126 \mathrm{mg} / \mathrm{dL}$ or more. Using the food frequency questionnaire and HbAlc in surveys, we examined the association between the annual food-frequencies of each food group and long-term blood glucose control.

Results: After adjustment for other covariates, HbAlc decreased significantly as the frequency of the intake of fish increased in each population ( $\mathrm{P}=0.001$ for all, $\mathrm{P}=0.043$ for men, $\mathrm{P}=0.001$ for women). The intake of mackerel played an especially important role in the control of diabetes. Among women, HbAlc decreased as the frequency of intake of legumes increased $(\mathrm{P}=0.029)$ and increased as the frequency of intake of staple carbohydrates increased $(\mathrm{P}=0.015)$. On the other hand, any intake of other food groups showed no significant relationship with HbAlc.

Conclusion: Frequent intake of fish in all populations and legumes in woman were associated with good glycemic control in diabetics. Frequent intake of carbohydrates was associated with elevated HbAlc in women.

Keywords: Food-frequency; Hemoglobin A, Glycosylated; HbAlc; Type 2 Diabetes; Korea National Health and Nutrition Examination Survey; Fishes

Received: August 31, 2011, Accepted: July 17, 2012

${ }^{*}$ Corresponding Author: Hwan-Sik Hwang

Tel: 82-2-2290-8741, Fax: 82-2-2281-7279

E-mail: fmhwang@hanyang.ac.kr

Korean Journal of Family Medicine

Copyright (C) 2012 The Korean Academy of Family Medicine

(a) This is an open-access article distributed under the terms of the Creative Commons Attribution Non-Commercial License (http://creativecommons.org/licenses/by-nc/3.0) which permits unrestricted noncommercial use, distribution, and reproduction in any medium, provided the original work is properly cited.

\section{INTRODUCTION}

Diabetes is a chronic illness that requires comprehensive treatment to prevent associated complications. Such treatment includes medical care from a physician-coordinated team, selfmanagement education, and problem-solving skills in the various aspects of diabetes management. Above all, the complications $\left(\right.$ micorvascular ${ }^{1)}$ or macrovascular $\left.{ }^{2}\right)$ associated with diabetes are closely linked to the extent of long-term blood glucose control, so a primary goal in the management of diabetes is the regulation of 
blood glucose to achieve near-normal blood glucose.

Recently, type 2 diabetes mellitus has increased in prevalence throughout the world. In Korea, lifestyles are becoming increasingly westernized, and physical inactivity is widely prevalent, making type 2 diabetes an important public health issue today. The prevalence of diabetes in Korea has increased from 6 - to 7 -fold from $1.5 \%$ to $10 \%$ during the past 40 years. ${ }^{3,4)}$ Diabetes-related mortality increased dramatically from 5.2 to 23.1 (a 4.4-fold increase) for men, and 3.8 to 22.8 for women (a 6.0fold increase) between 1983 and 2007.

An integral component of diabetes self-management education is medical nutrition therapy (MNT). MNT is important in managing diabetes to prevent or slow the rate of development of diabetes complications, and optimize energy intake and macronutrient composition. Although controversial, there are several recommendations by the American Diabetes Association regarding MNT: 1) Carbohydrate intake from fruits, vegetables, whole grains, legumes, and low-fat milk is encouraged.

2) Monitoring carbohydrate intake, whether by carbohydrate counting, exchanges, or experienced-based estimation, is recommended, and the use of glycemic index and load may provide a modest additional benefit. 3) Consumption of a variety of fiber-containing foods is recommended. 4) Limitation of saturated fat to $7 \%$ of total calories. 5) Two or more servings of fish per week is recommended. ${ }^{6)}$

The relation of specific foods and nutrients such as vegetables, ${ }^{7)}$ dietary fiber, ${ }^{8)}$ and glycemic load ${ }^{9)}$ to risk of type 2 diabetes has been examined in many studies, but few have addressed the association with long-term blood glucose control in diabetes. Although long-term glycemic control through caloric restriction is most important in diabetes patients, it is also important to maintain individual pleasure of eating. However, there has been little research on the optimal dietary macronutrient composition and the extent of glycemic control in relation to each food group for patients with type 2 diabetes. Thus, many physicians are reluctant to choose foods and decide the intake frequency of each food for their patients.

Glycated hemoglobin (HbAlc) is a biomarker of longterm glucose control that reflects blood glucose concentrations over the previous 6 to 8 weeks. ${ }^{10)}$ As shown previously, a single measurement of $\mathrm{HbAlc}$ is reliable to classify diabetes and predict the vascular complications according to long-term blood glucose concentration. $^{11)}$

In this study, we examined the food-frequencies of each food group and evaluated the relationship between the intake frequencies of certain food groups and long-term blood glucose control in Korean diabetes patients using data collected from the 4th Korea National Health and Nutrition Examination Survey.

\section{METHODS}

\section{Study Population}

The study population was derived from the data of the 4th Korea National Health and Nutrition Examination Survey during 2007 to 2009 . These surveys gathered data about the health and nutritional status of 24,871 subjects in various regions of Korea. In the surveys, there were 1,561 diabetics who responded "yes" to the question "Are you currently suffering from diabetes?" or in whom serum fasting glucose was more than $126 \mathrm{mg} / \mathrm{dL}$. We excluded the 190 subjects who did not respond to the food frequency questionnaire (FFQ). Thus 1,371 subjects were included in this study. This study was approved by the ethics committee of a university hospital in Seoul.

\section{Food Group and Food Frequency}

In the FFQ of these surveys, there were 11 food groups consisting of 63 food items. Using this questionnaire, we reclassified the foods into 11 new food groups consisting of 58 food items. The new 11 food groups in this study were staple carbohydrates (rice and grains other than rice), other carbohydrates (ramen, noodles, breads, rice cakes, and confectionery), legumes (bean curd, legumes, and soybean milk), potatoes (potato and sweat potato), meat and eggs (beef, chicken, pork, ham/bacon/sausage, and egg), fish (mackerel, tuna, croaker, and Pollack), vegetables (Chinese cabbage, radish, radish leaves, bean sprouts, spinach, cucumber, red pepper, carrot, pumpkin, cabbage, tomato, and mushrooms), seaweeds (sea mustard and laver), fruits (tangerine, persimmon/dried persimmon, pear, watermelon, oriental melon, strawberry, grape, peach, apple, banana, and orange), milk and dairy products (milk, yogurt, and ice cream), and instant foods (hamburger, pizza, and fried foods).

The study participants checked the most appropriate answers 
to the 10 multiple-choice questions about the food frequency of each food item. The 10 multiple-choice answers were "1, 2, 3 times per day or $1,2-3,4-6$ times per week or $1,2-3$ times per month or 6-11 times per year or never." Using the questions, we calculated the annual food-frequency and the result was " $0,9,12$, $30,52,130,260,365,730$, and 1,095 times per year." The foodfrequency of each food group in this study was the sum of the annual food-frequencies of all foods included in the group.

\section{Assessment of Nondietary Covariates (Data Collection)}

The nondietary covariates collected from the data were sociodemographic characteristics (e.g., age, education, household income), anthropometric measurements (height, weight,

Table 1. General characteristics of subjects.

\begin{tabular}{|c|c|c|c|}
\hline Characteristic & Male $(\mathrm{n}=1,586,189)$ & Female $(\mathrm{n}=1,242,007)$ & P-value* \\
\hline Age (y) & $54.68 \pm 12.69$ & $61.70 \pm 12.71$ & $<0.001$ \\
\hline Abdominal circumference $(\mathrm{cm})$ & $88.99 \pm 8.67$ & $87.37 \pm 9.89$ & $<0.001$ \\
\hline $\mathrm{BMI}\left(\mathrm{kg} / \mathrm{m}^{2}\right)$ & $25.20 \pm 3.36$ & $25.66 \pm 3.70$ & $<0.001$ \\
\hline Serum fasting glucose (mg/dL) & $146.46 \pm 45.55$ & $149.87 \pm 53.60$ & $<0.001$ \\
\hline HbAlc (\%) & $7.17 \pm 1.45$ & $7.47 \pm 1.62$ & $<0.001$ \\
\hline Total cholesterol (mg/dL) & $189.00 \pm 40.02$ & $200.03 \pm 40.98$ & $<0.001$ \\
\hline HDL cholesterol (mg/dL) & $42.85 \pm 10.98$ & $47.30 \pm 11.99$ & $<0.001$ \\
\hline Triglyceride (mg/dL) & $207.67 \pm 182.70$ & $167.32 \pm 98.62$ & $<0.001$ \\
\hline Duration of diabetes (y) & $7.31 \pm 7.47$ & $8.23 \pm 7.75$ & $<0.001$ \\
\hline Smoking (pack year) & $20.99 \pm 20.83$ & $1.58 \pm 6.27$ & $<0.001$ \\
\hline Physical activity $^{\dagger}$ & $3,339.12 \pm 4,562.51$ & $2,519.90 \pm 3,693.53$ & $<0.001$ \\
\hline Alcohol $^{\ddagger}$ & $6,507.45 \pm 9,685.80$ & $609.74 \pm 2,598.71$ & $<0.001$ \\
\hline \multicolumn{4}{|c|}{ Monthly household income (quartile) } \\
\hline Low & $463,426(30.1)$ & $327,622(28.0)$ & $<0.001^{\S}$ \\
\hline Middle low & $361,963(23.5)$ & $348,819(29.8)$ & \\
\hline Middle high & $342,893(22.3)$ & $234,493(20.0)$ & \\
\hline High & $372,641(20.2)$ & $259,435(22.2)$ & \\
\hline \multicolumn{4}{|l|}{ Education } \\
\hline$\leq$ Primary school & $383,962(24.5)$ & $819,074(66.4)$ & $<0.001^{\S}$ \\
\hline$\leq$ Middle school & $296,729(18.9)$ & $127,241(10.3)$ & \\
\hline$\leq$ High school & $506,839(32.3)$ & $243,411(19.7)$ & \\
\hline$\geq$ College & $382,835(24.4)$ & $43,052(3.5)$ & \\
\hline \multicolumn{4}{|c|}{ Current therapeutic status of diabetes } \\
\hline Insulin (yes) & $62,311(4.0)$ & $67,804(5.5)$ & $<0.001^{\|}$ \\
\hline Oral medication (yes) & $813,407(51.7)$ & $769,566(62.1)$ & $<0.001^{\|}$ \\
\hline Behavioral therapy (yes) & $384,241(24.4)$ & $282,200(22.8)$ & $<0.001^{\|}$ \\
\hline
\end{tabular}

Values are presented as mean \pm SD or number (\%).

BMI: body mass index, HbAlc: glycated hemoglobin, HDL: high density lipoprotein.

*Calculated by Student t-test. ${ }^{\dagger}$ Calculated by the International Physical Activity Questionnaire score, metabolic equivalents-min/wk. ${ }^{\ddagger}$ Annual average amount of the alcohol drinking (gm/y). ${ }^{\S}$ Calculated by linear by linear test. ${ }^{\| C}$ Calculated by Pearson $\chi^{2}$ test. 
abdominal circumference), serum fasting glucose, $\mathrm{HbAlc}$, total cholesterol, high density lipoprotein (HDL) cholesterol, triglyceride (TG), smoking, alcohol consumption, physical activity, duration of diabetes, and current medication status.

From the data, we calculated the body mass index ([BMI], calculated as $\mathrm{kg} / \mathrm{m}^{2}$ ), the daily average amount of current smoking, the annual average amount of alcohol consumption, and the International Physical Activity Questionnaire score ${ }^{12)}$ for physical activity.

\section{Statistical Analysis}

All analyses were performed by reflecting weighted values at the stratification of the samples applied to the Korea National Health and Nutrition Examination Survey. The characteristics of the study subjects were compared using the Student t-test. Household income and education were compared by the linear by linear test while the current medication status was compared by the Pearson $\chi^{2}$ test. Multiple linear regression analyses were used to evaluate the relationship between food frequency and $\mathrm{HbAlc}$, while controlling for other covariates, including age, BMI, physical activity, smoking, and alcohol consumption. Statistical analyses were performed by using SPSS ver. 18.0 (SPSS Inc., Chicago, IL, USA).

\section{RESULTS}

General characteristics of the subjects are shown in Table 1. With statistical significance, the age, BMI, fasting glucose, $\mathrm{HbAlc}$, total cholesterol, HDL cholesterol, duration of diabetes, and therapy of diabetes by insulin and oral medication were higher in women, while the abdominal circumference, TG, smoking, physical activity, alcohol consumption, household income, education, and behavioral therapy frequency were higher in men.

The food-frequencies of each food group are shown in Table 2. There is a statistically significant male predominance in the food-frequencies of other carbohydrates, meat and eggs, fish, vegetables, seaweeds, milk and dairy products, and instant foods.

Table 3 shows the relationship between the food frequency and $\mathrm{HbAlc}$. After adjustment for other covariates, HbAlc decreased significantly as the frequency of the intake of fish increased all populations $(\mathrm{P}=0.001$ for all, $\mathrm{P}=0.043$ for men, $\mathrm{P}=0.001$ for women). Among women, HbAlc decreased as the frequency of intake of legumes increased $(\mathrm{P}=0.029)$ and increased as the frequency of intake of staple carbohydrates increased $(\mathrm{P}=0.015)$. On the other hand, any intake of other food groups showed no significant relationship with $\mathrm{HbAlc}$.

Fish consumption consistently abated $\mathrm{HbAlc}$, so we evaluated the relationship between each fish type included in

Table 2. Weekly food frequency (times/wk) of each food group.

\begin{tabular}{lccc}
\hline \multicolumn{1}{c}{ Food group } & Male $(\mathrm{n}=1,586,189)$ & Female $(\mathrm{n}=1,242,007)$ & P-value* \\
\hline Staple carbohydrates & $31.94 \pm 9.76$ & $33.55 \pm 9.54$ & $<0.001$ \\
Other carbohydrates & $3.41 \pm 3.04$ & $2.54 \pm 2.48$ & $<0.001$ \\
Legumes & $9.95 \pm 8.46$ & $12.65 \pm 9.44$ & $<0.001$ \\
Potatoes & $1.61 \pm 1.47$ & $1.64 \pm 1.85$ & $<0.001$ \\
Meat and eggs & $4.69 \pm 3.61$ & $3.13 \pm 2.77$ & $<0.001$ \\
Fishes & $2.13 \pm 1.87$ & $1.80 \pm 1.67$ & $<0.001$ \\
Vegetables & $34.04 \pm 13.81$ & $30.37 \pm 13.19$ & $<0.001$ \\
Seaweeds & $3.52 \pm 2.76$ & $3.36 \pm 3.04$ & $<0.001$ \\
Fruits & $7.09 \pm 5.84$ & $8.01 \pm 7.07$ & $<0.001$ \\
Milk and dairy products & $3.41 \pm 3.78$ & $3.12 \pm 4.02$ & $<0.001$ \\
Instant foods & $0.44 \pm 0.65$ & $0.27 \pm 0.41$ & $<0.001$ \\
\hline
\end{tabular}

Values are presented as mean $\pm \mathrm{SD}$.

*Calculated by Student t-test. 
the group and HbAlc. The results are shown in Table 4. With statistical significance, the mackerel decreased $\mathrm{HbAlc}$ in total and in women ( $\mathrm{P}=0.022$ for total, $\mathrm{P}=0.006$ for women).

\section{DISCUSSION}

Notably, fish consumption affected HbAlc inversely in both men and women. From previous studies, the consumption of fish and related nutrients (especially long-chain omega-3 fatty acids) seems to have various metabolic effects on patients with diabetes, and the risks and benefits remain controversial. Intake of fish and related nutrients resulted in beneficial effects on glucose tolerance, ${ }^{13)}$ microalbuminuria, ${ }^{14)}$ and cardiovascular disease (CVD) ${ }^{15)}$ while deteriorated glycemic control. ${ }^{16)}$ Furthermore, environmental pollutants found in fish such as dioxins may raise the risk of diabetes in the recent study. ${ }^{17)}$ However, we found that frequent intake of fish improved glycemic control in patients with diabetes. Mackerel played a particularly important role among the types of fish consumed.

Staple carbohydrates had negative effects on $\mathrm{HbAlc}$ in women. Korean main dishes include carbohydrate foods such as rice, brown rice, and barley. The result of this study demonstrated this fact, as seen in the staple foods frequency. However, the

Table 3. Association between glycated hemoglobin and food-frequency (times/wk).

\begin{tabular}{|c|c|c|c|c|c|c|c|c|c|}
\hline \multirow{2}{*}{ Food group } & \multicolumn{3}{|c|}{ Total $(\mathrm{n}=2,828,196)$} & \multicolumn{3}{|c|}{ Male (n=1,586,189) } & \multicolumn{3}{|c|}{ Female $(\mathrm{n}=1,242,007)$} \\
\hline & $\beta$ & SE & P-value* & $\beta$ & SE & P-value* & $\beta$ & SE & P-value* \\
\hline Staple carbohydrates & 0.005 & 0.007 & 0.430 & -0.008 & 0.009 & 0.408 & 0.022 & 0.009 & 0.015 \\
\hline Other carbohydrates & 0.037 & 0.023 & 0.098 & 0.028 & 0.032 & 0.384 & 0.045 & 0.030 & 0.134 \\
\hline Legumes & -0.007 & 0.006 & 0.295 & -0.003 & 0.008 & 0.752 & -0.019 & 0.009 & 0.029 \\
\hline Potatoes & 0.007 & 0.028 & 0.812 & 0.000 & 0.049 & 0.992 & 0.001 & 0.032 & 0.966 \\
\hline Meat and eggs & -0.011 & 0.023 & 0.639 & -0.027 & 0.025 & 0.273 & 0.039 & 0.029 & 0.176 \\
\hline Fishes & -0.097 & 0.029 & 0.001 & -0.076 & 0.037 & 0.043 & -0.137 & 0.041 & 0.001 \\
\hline Vegetables & -0.003 & 0.004 & 0.409 & -0.005 & 0.005 & 0.365 & 0.003 & 0.005 & 0.510 \\
\hline Seaweeds & 0.018 & 0.018 & 0.299 & 0.025 & 0.023 & 0.288 & 0.002 & 0.027 & 0.940 \\
\hline Fruits & 0.004 & 0.009 & 0.651 & 0.006 & 0.014 & 0.652 & -0.001 & 0.011 & 0.897 \\
\hline Milk and dairy products & 0.022 & 0.014 & 0.134 & 0.032 & 0.022 & 0.144 & 0.008 & 0.020 & 0.673 \\
\hline Instant foods & -0.108 & 0.123 & 0.382 & -0.010 & 0.141 & 0.943 & -0.285 & 0.185 & 0.124 \\
\hline
\end{tabular}

HbAlc: glycated hemoglobin.

*Calculated by multiple linear regression analysis adjusted for age, body mass index, physical activity, smoking, and alcohol drinking.

Table 4. Association between glycated hemoglobin and food-frequency (times/wk) of fishes.

\begin{tabular}{|c|c|c|c|c|c|c|c|c|c|}
\hline \multirow{2}{*}{ Food group } & \multicolumn{3}{|c|}{ Total $(\mathrm{n}=2,828,196)$} & \multicolumn{3}{|c|}{ Male $(\mathrm{n}=1,586,189)$} & \multicolumn{3}{|c|}{ Female $(\mathrm{n}=1,242,007)$} \\
\hline & $\beta$ & SE & P-value* & $\beta$ & SE & P-value* & $\beta$ & SE & P-value* \\
\hline Mackerel & -0.102 & 0.044 & 0.022 & -0.056 & 0.061 & 0.355 & -0.180 & 0.065 & 0.006 \\
\hline Tuna & 0.012 & 0.089 & 0.889 & 0.124 & 0.125 & 0.321 & -0.138 & 0.103 & 0.180 \\
\hline Croaker & -0.070 & 0.056 & 0.217 & -0.103 & 0.076 & 0.175 & -0.068 & 0.078 & 0.383 \\
\hline Pollack & -0.123 & 0.077 & 0.122 & -0.163 & 0.090 & 0.070 & -0.065 & 0.125 & 0.604 \\
\hline
\end{tabular}

HbAlc: glycated hemoglobin.

*Calculated by multiple linear regression analysis adjusted for age, body mass index, physical activity, smoking, and alcohol drinking. 
effect of carbohydrate composition on glycemic control is controversial. ${ }^{18-20)}$ In a recent study from Japan, it was shown that a dietary pattern using rice as a main meal may deteriorate glucose metabolism in Japanese men and women. ${ }^{21)}$ Our result that frequent intake of staple carbohydrates increased $\mathrm{HbAlc}$ in women corroborates that finding.

Legumes had a positive effect on $\mathrm{HbAlc}$ in women. Legumes are composed of various nutrients, including complex carbohydrates, vegetable protein, dietary fiber, oligosaccharides, and minerals. Legumes consisting of complex carbohydrates and dietary fiber are considered foods with low glycemic index, which are thought to be beneficial to patients with diabetes. ${ }^{22)}$

Several studies have suggested that the consumption of milk and dairy products may have beneficial effects on body weight, ${ }^{23,24)}$ insulin resistance syndrome, ${ }^{25,26)}$ and cardiovascular disease. $^{27,28)}$ However, there is few data relating dairy intake frequency to blood glucose control of diabetes. Recently, one study found that low-fat dairy products reduced the risk of diabetes. ${ }^{29)}$ However, we could not find the association between intake of milk and dairy products and $\mathrm{HbAlc}$.

There are several limitations in this study. First, the crosssectional design of this study lacks the power to prove causality, and long-term follow-up studies are needed to establish a causal relationship between food-frequency and $\mathrm{HbAlc}$. Second, we used food-frequency in considering the dietary habits in the population because of the form of the FFQ in the surveys. Thus, this study failed to consider the true amount of food consumed at one time.

In conclusion, frequent intake of fish was associated with glycemic control in patients with diabetes. Especially in women, frequent intake of staple carbohydrates was associated with elevated $\mathrm{HbAlc}$, and frequent intake of legumes was associated with decreased $\mathrm{HbAlc}$

\section{CONFLICT OF INTEREST}

No potential conflict of interest relevant to this article was reported.

\section{REFERENCES}

1. The Diabetes Control and Complications Trial Research Group. The effect of intensive treatment of diabetes on the development and progression of long-term complications in insulin-dependent diabetes mellitus. N Engl J Med 1993;329: 977-86.

2. Grundy SM, Benjamin IJ, Burke GL, Chait A, Eckel RH, Howard BV, et al. Diabetes and cardiovascular disease: a statement for healthcare professionals from the American Heart Association. Circulation 1999;100:1134-46.

3. Kim KS, Choi CH, Lee DY, Kim EJ. Epidemiological study on diabetes mellitus among rural Korean. J Korean Diabetes Assoc 1972;1:17-24.

4. Ministry of Health and Welfare. Korea Health Statistics 2010: Korea National Health and Nutrition Examination Survey (KNHANES V-1) [Internet]. Seoul: Ministry of Health and Welfare; 2011 [cited 2011 Aug 8]. Available from: http:// www.kosis.kr/.

5. Statistics Korea. Annual Report on the Cause of Death Statistics [Internet]. Daejeon: Statistics Korea [cited 2011 Aug 8]. Available from: http://kosis.kr/.

6. American Diabetes Association, Bantle JP, Wylie-Rosett J, Albright AL, Apovian CM, Clark NG, et al. Nutrition recommendations and interventions for diabetes: a position statement of the American Diabetes Association. Diabetes Care 2008;31 Suppl 1:S61-78.

7. Ford ES, Mokdad AH. Fruit and vegetable consumption and diabetes mellitus incidence among U.S. adults. Prev Med 2001;32:33-9.

8. Schulze MB, Schulz M, Heidemann C, Schienkiewitz A, Hoffmann K, Boeing H. Fiber and magnesium intake and incidence of type 2 diabetes: a prospective study and metaanalysis. Arch Intern Med 2007; 167:956-65

9. Salmeron J, Manson JE, Stampfer MJ, Colditz GA, Wing AL, Willett WC. Dietary fiber, glycemic load, and risk of noninsulin-dependent diabetes mellitus in women. JAMA 1997; 277:472-7.

10. Koenig RJ, Cerami A. Hemoglobin A Ic and diabetes mellitus. Annu Rev Med 1980;31:29-34.

11. Nathan DM, Singer DE, Godine JE, Harrington CH, Perlmuter LC. Retinopathy in older type II diabetics. 
Association with glucose control. Diabetes 1986;35:797-801.

12. Guidelines for data processing and analysis of the International Physical Activity Questionnaire (IPAQ): short and long forms [Internet]. [place unknown]: The IPAQ group; 2005 [cited 2011 Aug 8]. Available from: http://www. ipaq.ki.se/scoring.pdf.

13. Adler AI, Boyko EJ, Schraer CD, Murphy NJ. Lower prevalence of impaired glucose tolerance and diabetes associated with daily seal oil or salmon consumption among Alaska Natives. Diabetes Care 1994;17:1498-501.

14. Mollsten AV, Dahlquist GG, Stattin EL, Rudberg S. Higher intakes of fish protein are related to a lower risk of microalbuminuria in young Swedish type 1 diabetic patients. Diabetes Care 2001;24:805-10.

15. Stone NJ. Fish consumption, fish oil, lipids, and coronary heart disease. Circulation 1996;94:2337-40.

16. Friday KE, Childs MT, Tsunehara CH, Fujimoto WY, Bierman EL, Ensinck JW. Elevated plasma glucose and lowered triglyceride levels from omega-3 fatty acid supplementation in type II diabetes. Diabetes Care 1989;12:276-81.

17. Lee DH, Lee IK, Song K, Steffes M, Toscano W, Baker BA, et al. A strong dose-response relation between serum concentrations of persistent organic pollutants and diabetes: results from the National Health and Examination Survey 1999-2002. Diabetes Care 2006;29:1638-44.

18. Kodama S, Saito K, Tanaka S, Maki M, Yachi Y, Sato M, et al. Influence of fat and carbohydrate proportions on the metabolic profile in patients with type 2 diabetes: a metaanalysis. Diabetes Care 2009;32:959-65.

19. Xu J, Eilat-Adar S, Loria CM, Howard BV, Fabsitz RR, Begum $\mathrm{M}$, et al. Macronutrient intake and glycemic control in a population-based sample of American Indians with diabetes: the Strong Heart Study. Am J Clin Nutr 2007;86:480-7.

20. Leon-Sanz M, Garcia-Luna PP, Sanz-Paris A, GomezCandela C, Casimiro C, Chamorro J, et al. Glycemic and lipid control in hospitalized type 2 diabetic patients: evaluation of 2 enteral nutrition formulas (low carbohydrate-high monounsaturated fat vs high carbohydrate). JPEN J Parenter Enteral Nutr 2005;29:21-9.

21. Nanri A, Mizoue T, Yoshida D, Takahashi R, Takayanagi R. Dietary patterns and A1C in Japanese men and women. Diabetes Care 2008;31:1568-73.

22. Jenkins DJ, Wolever TM, Taylor RH, Barker H, Fielden H, Baldwin JM, et al. Glycemic index of foods: a physiological basis for carbohydrate exchange. Am J Clin Nutr 1981;34: 362-6.

23. Lin YC, Lyle RM, McCabe LD, McCabe GP, Weaver CM, Teegarden D. Dairy calcium is related to changes in body composition during a two-year exercise intervention in young women. J Am Coll Nutr 2000;19:754-60.

24. Zemel MB. Mechanisms of dairy modulation of adiposity. J Nutr 2003;133:252S-6.

25. Mennen LI, Balkau B, Vol S. Tissue-type plasminogen activator antigen and consumption of dairy products. The DESIR study. Data from an Epidemiological Study on Insulin Resistance Syndrome. Thromb Res 1999;94:381-8.

26. Pereira MA, Jacobs DR Jr, Van Horn L, Slattery ML, Kartashov AI, Ludwig DS. Dairy consumption, obesity, and the insulin resistance syndrome in young adults: the CARDIA Study. JAMA 2002;287:2081-9.

27. Bostick RM, Kushi LH, Wu Y, Meyer KA, Sellers TA, Folsom AR. Relation of calcium, vitamin D, and dairy food intake to ischemic heart disease mortality among postmenopausal women. Am J Epidemiol 1999;149:151-61.

28. Ness AR, Smith GD, Hart C. Milk, coronary heart disease and mortality. J Epidemiol Community Health 2001;55:37982.

29. Liu S, Choi HK, Ford E, Song Y, Klevak A, Buring JE, et al. A prospective study of dairy intake and the risk of type 2 diabetes in women. Diabetes Care 2006;29:1579-84. 